\title{
EL COMIC MULTILINEAL INTERACTIVO Un Modelo Para Estimular La Lectura Digital
}

\section{Ernesto Javier Fernández Tovar - UFRGS / PPGIE - ernestojavi@ hotmail.com}

Resumen: Este artículo presenta un modelo de comic multilineal construido como instrumento en una investigación sobre los efectos del uso de hipertextos en el desarrollo de competencias para el aprendizaje. Se presenta un sustento teórico sobre el estado del analfabetismo y los hábitos de lectura en Latinoamérica, la lectura en medios digitales y el uso del comic en la educación. El artículo presenta un experimento con el modelo de comic multilineal y compara la comprensión y la motivación de 30 estudiantes divididos en un grupo experimental y un grupo de control. Los resultados del experimento demuestran que el modelo multilineal implementado en el comic interactivo motiva la lectura por placer en estudiantes de 9 a 12 años.

Palabras claves: Lectura, comic multilineal, hipertexto.

\section{THE COMIC MULTILINEAR INTERACTIVE A Model to Stimulate the Digital Reading}

Abstract: This paper presents a model of Comic Multilinear built as a tool in research on the effects of using hypertext in the development of learning skills. A theoretical basis on the status of literacy and reading habits in Latin America, reading in digital media and the use of comics in education is presented. The article presents an experiment with comic multilinear model and compares the understanding and motivation of 30 students divided into an experimental group and a control group. The experiment results show that the model implemented multilinear interactive comic encourages reading for pleasure in students 9 to 12 years.

Keywords: Reading, comic multilinear, hypertext.

\section{Introducción.}

Nacemos sin la capacidad de leer, esta habilidad requiere que regiones específicas del cerebro generen nuevas conexiones neuronales que solo serán posibles entre los 3 y 4 años de edad, cuando se adquiere la capacidad de identificar los símbolos, comprender el mensaje y asumir una postura actitudinal frente a lo que se lee. Para Maryanne Wolf (2008) el diseño del cerebro hace posible la lectura y el diseño de la lectura cambia al cerebro en múltiples formas que aún están en evolución. Contextos como la familia y la escuela son determinantes en el desarrollo de la capacidad lectora y definen la manera como el niño se integra al mundo simbólico donde se desarrollará.

La lectura y la forma como nos comunicamos hoy son el producto de la evolución que ha vivido la humanidad hasta llegar a la era de la información, según Lévy (1999) estas nuevas relaciones comunicacionales que emergen en la posmodernidad, están influyendo en los procesos de aprendizaje de los estudiantes. Las Tecnologías de la Información y Comunicación (TIC) hacen posibles nuevos contextos para que circulen los saberes, otros lenguajes y símbolos han cobrado protagonismo en nuestras aulas de clase, la escuela verbal expira frente a estilos de aprendizajes divergentes que priorizan lo visual. Salvat (2000) califica estos efectos como "revolucionarios", sobre todo a los modos de comunicarnos que cada día dependen más de los avances tecnológicos, afectando rasgos culturales e incluso afectivos, resalta que la información digitalizada ya no se limita al texto escrito sino que incluye la imagen, el sonido y el video. Según Holtzman (1994) el arte digital propone universos digitales, mundos que sólo son posibles de crear a través 
de los sistemas computacionales, tiene el potencial para recrear ideas y generar emociones de un modo que otros medios no podrían hacerlo.

En este proceso de virtualización de las diferentes narrativas nacen las versiones digitales de medios como los libros, la fotografía, los mapas y entre otros el comic. Es así como el universos virtual deja de ser externo a la escuela y permea el aula de clase, son diversos los estudios sobre la narrativa digital en el contex to educativo, Cecchin (2014) afirma que el trabajo con textos hipermediáticos desarrolla la creatividad y la criticidad, permitiendo que los estudiantes se atrevan a crear textos híbridos construidos con múltiples lenguajes. En ese mismo sentido Ohler (2008) plantea que el relato digital se convierte en una forma efectiva de enseñar, ayuda a los estudiantes a desarrollar la creatividad y las habilidades de innovación necesarias para resolver problemas importantes en forma imaginativa, ofreciendo un potencial comunicativo para recuperar la motivación de los estudiantes.

Este artículo propone un modelo de comic digital multilineal que nace como instrumento en una investigación sobre los efectos del uso de hipertextos en el desarrollo de competencias para el aprendizaje, compara la comprensión y la motivación de 30 estudiantes que en dos grupos diferentes abordan una misma lectura usando dos tipos de comics diferentes, el primero el comic multilineal interactivo y el segundo el comic digital tradicional. Los resultados del experimento demuestran que el modelo multilineal implementado en el Comic interactivo motiva la lectura por placer en estudiantes de 9 a 12 años.

\section{Analfabetismo, hábitos y tendencias de la lectura en América Latina.}

Los hábitos de lectura en los países latinoamericanos están influenciados por una deuda social que se refleja en los altos índices de analfabetismo, en las últimas décadas se han realizado avances significativos para mejorar sus indicadores sin embargo este factor determinante para el acceso a la lectura persiste. Según el Sistema de Información de Tendencias Educativas en América Latina (SITEAL) (2008), Guatemala se muestra con el mayor índice de analfabetismo con una disminución que pasó del $31.7 \%$ en el año 2.000 al $25.2 \%$ en el año 2008, para la misma fecha Argentina y Uruguay ostentan el menor índice de analfabetismo con el $1.2 \%$ y $1.9 \%$ respectivamente, sin embargo es preocupante la brecha creada por las desigualdades geográficas en países como Brasil y Colombia donde las tasas de analfabetismo rural son entre 3 y 5 veces mayores que las urbanas. SITEAL (2008) afirma que Los países que tienen mayores porcentajes de analfabetismo en población de 15 a 24 años son aquellos donde el acceso al sistema educativo es más desigual y no han logrado garantizar este derecho fundamental.

Reconocer esta realidad nos permite adquirir una visión más consecuente con los hábitos y tendencias de la lectura identificados en la región. Según Failla (2012) el Centro Regional para el Fomento del Libro en América Latina y el Caribe CERLALC, trabaja desde el 2005 en la estructuración de un método común de medida que busca recoger un conocimiento profundo de los escenarios, las experiencias y las costumbres concretas alrededor de la lectura, aplicándolo en todos los países de la región. Siendo Brasil uno de los primeros países en implementarlo en el 2007. La propuesta metodológica que fue optimizada en el 2011 investiga y mide el comportamiento del lector, permite identificar signos sobre la necesidad de desarrollar estrategias que motiven la lectura desde temprana edad enfocándonos en estimular el placer por esta actividad.

Failla (2012) presenta entre otros los siguientes resultados que caracterizan el perfil lector del continente latinoamericano y tienen relación con el objetivo del presente artículo:

Lectores y No lectores: El estudio considera no lectores a quienes no tienen el hábito de la lectura, esta variable muestra que cerca de la mitad de la población latinoamericana se 
declara No lector, los resultados muestran que en Chile durante el 2011 identificaron un $20 \%$, en Brasil y Venezuela el porcentaje fue de 50\%, en Argentina el $45 \%$ y en Colombia el $44 \%$.

Motivación para leer: Cuando son analizados los resultados de los motivos de quienes se declaran lectores, el placer por la lectura marca una gran diferencia entre un lector habitual y un lector esporádico, en España un $86 \%$ de los lectores lo hacen por placer, en Argentina un $70 \%$ y en Brasil un 49\%, la lectura por cuestiones académica tiene menor peso especialmente en Brasil, Chile y Argentina, siendo Brasil, Portugal, Venezuela, México y Chile donde la lectura con propósitos de actualización cultural y conocimiento general es mayor. La razón más invocada para no leer es la falta de tiempo, con porcentajes que van desde el 53\% de Brasil hasta el 28\% de Chile, y en segundo lugar la falta de interés, en esta categoría encontramos a Colombia donde la falta de interés es mencionada por un $67 \%$.

Lectura de libros y otros materiales: El índice de lectura de libros más alto está en Argentina con un 55\% seguido por Chile con un 51\%, el promedio de consumo de libros en Brasil es de 4 libros por año, superado por Chile y Argentina con un 5,4\% y 4,6\% respectivamente, en España se registra una media de 10,3 libros leídos por habitante lo que contrasta con el 2,2\% de libros leídos por año en Colombia.

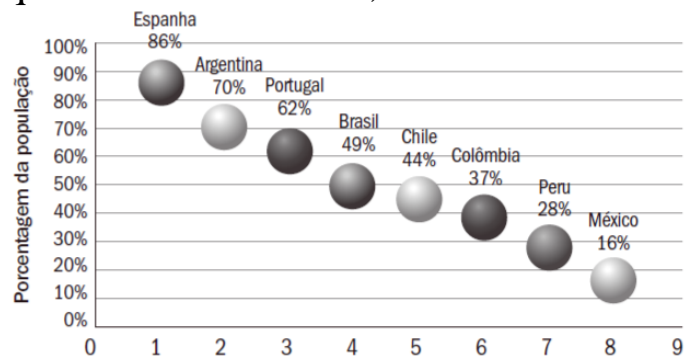

Figura 1: Porcentaje de lectores por Placer.

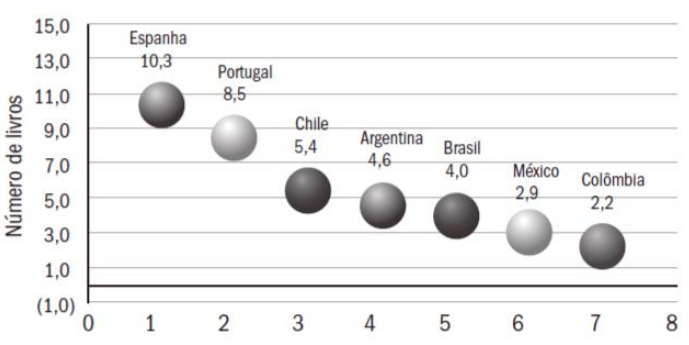

Figura 2: Número de libros leídos por año.

Fuente: Failla (2012)

\section{La lectura em médios digitales.}

La creciente penetración de internet, el aumento de la velocidad en la conexión y el consumo masivo de dispositivos electrónicos móviles conectados a la gran red, están cambiando el contexto de la lectura. Gutiérrez (2009) plantea que estamos frente al nacimiento de lo que él denomina "nuevos lectores" y consecuentemente frente a nuevas formas del libro, el autor pronostica que viviremos la modificación social del concepto del libro, indica que probablemente el "Bloque de papel" como visualizamos hoy al libro no desaparezca, pero asegura que el concepto de libro se extenderá, y efectivamente estamos presenciando la aparición de nuevos soportes que se adaptan a nuevos formatos y estructuras específicas de información. Esta evolución del hardware y del software sobre los cuales se ejecuta la lectura en los universos digitales, exigen que los nuevos lectores construyan lo que Gutierrez (2009) denomina "perfiles emergentes en la convergencia digital" que requiere según el autor lectores flexibles con un doble rol de lector/escritor, ideal para sacar provecho de las potencialidades que facilitan los formatos hipermediales y el desarrollo de habilidades para la interacción y construcción de redes en las que se teja comunidad y se movilice como actor político de los mundo virtuales carentes de fronteras.

La industria del libro, las revistas y el comic empiezan a adaptarse a los desafíos que plantean los avances tecnológicos; la producción, circulación y distribución de estos medios ha vivido en las dos últimas décadas transformaciones aceleradas que obligaron a muchas editoriales a cambiar su modelo de negocio, según la firma Aptara, citada por 
CERLALC (2012), en Estados Unidos durante el 2009 el 53\% de los editores estaba produciendo libros electrónicos y el $60 \%$ de los que no lo estaban haciendo planteaba hacerlo en el corto plazo, y en la última encuesta realizada por esta firma en 2012 el 80\% de los entrevistados estaban produciendo libros electrónicos. Este fenómeno empieza a tener sus efectos en América Latina, según CERLAC (2012) mientras que en el 2003 solo el 4\% de los libros registrados en la agencia nacional del ISBN eran libros electrónicos, en el 2011 el porcentaje asciende al 15\%, el 90\% de los títulos registrados se concentran en Brasil, Colombia, Argentina y México.

En el campo de educativo la producción y consumo de materiales para la lectura en medios digitales se encuentra inmersa en un entramado de nuevos conceptos que día a día están reevaluándose, para Astudillo, et al, (2011) “El Material Educativo Digital” (MED) engloba todo recurso digital diseñado con la intencionalidad pedagógica, en este concepto el autor distingue los denominados Recursos Educativos Abiertos (REA) y los Objetos de Aprendizaje (OA).

El volumen de producción, la diversidad de formatos y la necesidad de establecer unos controles mínimos para la clasificación, búsqueda y garantía de calidad del material educativo digital dieron origen al concepto de "Repositorio" definido por Lopez (2005) como un "conjunto de servicios para el desarrollo, almacenamiento, administración, localización y recuperación de todo tipo de contenido digital". En la actualidad empieza a penetrar en la región el concepto del MOOC acrónimo en inglés de Massive Online Open Courses (o Cursos online masivos y abiertos), según Cormier (2010) se trata de un curso a distancia, accesible mediante internet al que se puede inscribir cualquier persona y prácticamente no tiene límite de participantes. En Latinoamérica universidades y gobiernos hacen esfuerzos para construir y fortalecer repositorios de material educativo digital. Astudillo, et al, (2011) muestra que hoy se puede contar en la región con diversos repositorios oficiales con material de buena calidad disponibles de forma abierta para ser utilizados en el ejercicio de la lectura digital.

\section{El Comic, evolución y uso educativo.}

Comic en inglés, Historieta en español o Quadrinhos en portugués, según Montijano (2006) es una narrativa iconográfica que mezcla texto e imágenes, se desarrolló en Estados Unidos a finales del siglo XIX. Según el diccionario de la Real Academia Española, la palabra Cómic proviene del inglés y hace referencia tanto a una serie o secuencia de viñetas con desarrollo narrativo, como a un libro o revista que contiene estas viñetas. Montijano (2006) afirma que los primeros Comics aparecieron en los periódicos de Nueva York: el World (New York World), propiedad de Joseph Pulitzer desde 1883, y el Morning Journal, adquirido por WilliamRandolph Herast en 1895. Su característica estética ha sufrido pocas modificaciones en una historia de más de 100 años, su origen cómico ha mudado a múltiples géneros, pasando por la aventura, el romanticismo, la sátira y el político, siendo la posguerra en 1950 la etapa de renacimiento con un enfoque adulto y polémico que moldeó el estilo que ha caracterizado a los grandes dibujantes del comic europeo y norteamericano. En Latinoamérica cronológicamente la primera representante del género es Mafalda. Según Montijano (2006) el aporte suramericano a la universalización del comic fue a través de la precoz, contestataria y polémica Mafalda (1964), de gruesa cabeza sobre diminuto cuerpo, producto de la genialidad del Argentino Quino (Joaquín Salvador Lavado); la polémica líder dirigía su clan formado por personajes como Manolito, Felipe, Susanita, Miguelito y el bebé Guille.

En el contexto de la escuela, la dinámica de elaborar un guión gráfico que narre una historia y combine lectura, escritura y creación de imágenes en formato de historieta, es 
una actividad atractiva desde su utilidad didáctica y pedagógica, Wilson (2013) plantea que el formato lúdico del Comic lo hace fácil de comprender para los estudiantes, su estética gráfica los impulsa a seguir la secuencia de la historia, la síntesis textual y la invitación a complementar la historia a partir de su imaginación frente a la propuesta visual, motiva a los estudiantes a la comprensión del mensaje implícito que se está narrando. El comic educativo no tiene variaciones profundas con respecto al comic tradicional en cuanto al soporte ni a la forma, la diferencia radica en la intencionalidad con que se piensa, el lenguaje utilizado y el mensaje de las historias.
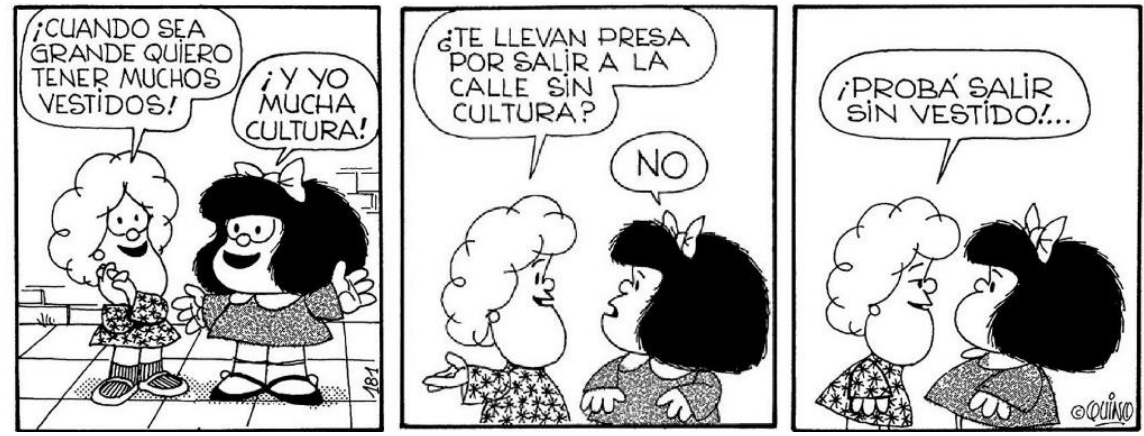

Fuente: http://www.quino.com.ar/mafalda-digital/

Figura 3: Tira cómica de Mafalda, versión digital

Tal como ha sucedido con el libro, las revistas, los mapas y otras piezas comunicativas, el comic también ha sido transformado por la llegada de los avances tecnológicos en la era de la información. Para López (2013) la integración de texto, sonido, imagen y los hipermedios permiten que el estudiante sea autor y se atreva a diseñar sus propias piezas comunicativas, potenciando sus habilidades para investigar, organizando sus ideas en forma secuencial e incorporándolas en forma de historieta. Según el autor los Cómics, como secuencias narrativas, pueden construirse con textos escritos u orales, imágenes y sonidos de fondo; a esta mezcla de medios se le denomina Transmedia.

En la actualidad existe una gran oferta de aplicaciones móviles y sitios web que permiten la creación fácil de tiras cómicas digitales donde maestros y estudiantes pueden usar su creatividad para presentar visualmente secuencias narrativas con fines educativos, entre otras están Pixton, GoAnimate, ComicMaker, Toondo, Bitstrips, Comic Strip It, Creaza Cartoonist. Sin embargo el comic digital como una recreación electrónica del comic impreso en medio físico, ha mantenido a lo largo de su existencia la linealidad de las historias que narra, esta invariabilidad creó la necesidad de construir la propuesta de modelo multilineal que se presenta en este artículo, el cual fue desarrollado como parte de los instrumentos de recolección de datos de una investigación que tenía como objetivo indagar sobre los efectos que causa el uso del hipertexto en el desarrollo de competencias para el aprendizaje, aun cuando el objetivo inicial de la investigación no era construir el modelo de Comic Multilineal, la necesidad de elaborar objetos de aprendizaje que incorporen el hipertexto permitió que se construyera este modelo de narración multilineal bajo la estética del comic.

\section{Multilinealidad en la narrativa digital}

Lo digital modifica la forma de narrar historias, tanto el escritor como el lector se enfrentan a nuevos desafíos marcados por la incertidumbre de los finales diversos, se parte del inicio único del relato que luego se transforma de manera impredecible al transitar por innumerables rutas argumentales. Para el escritor es perder el control del 
viaje literario y ganar la motivación del futuro incierto, el lector decide sobre el rumbo del relato con la recompensa de que al final podrá releer la historia con la misma motivación de la primera vez. Orihuela (1997) plantea que el soporte digital fractura la linealidad narrativa propia de los soportes analógicos, atribuye al texto una arquitectura poliédrica, lo expande y lo transforma, en ubicuo y social, esta es una posibilidad única de los entornos digitales que permiten una construcción discursiva hipertextual, al respecto Pérez (2003) afirmar que el hipertexto es un sistema de escritura que permite al lector un recorrido del texto sin seguir una estructura secuencial única (multilineal), enlazado entre sí de manera explícita con otros textos (intertextualidad) y donde en cierta medida es él y no el autor, quien construye su propio texto a través del camino de lectura elegido (descentralización discursiva).

Mudar a lo digital solo como un cambio de formato de almacenamiento sin aprovechar sus ventajas frente a lo análogo, es subutilizar los recursos tecnológicos. Rodríguez (2002) afirma que la narrativa digital debe basarse en tres componentes fundamentales: hipertexto (lectura no lineal del discurso), multimedia (utilización de diferentes soportes: animaciones, audio, vídeo...) e interacción (ejecución, por parte del usuario, del sistema a través de sus acciones). La llegada del Comic al formato digital le plantea retos para hacer parte de la narrativa digital. Según Orihuela (1997) sólo cabe interactividad en la medida en que hay hipertexto y sólo hay hipertexto en cuanto hay construcción no lineal (o multilineal), que es lo que permite la navegación del usuario. Este autor afirma que del mismo modo que la hipertextualidad es condición necesaria de la interactividad, la interactividad es condición necesaria de la narrativa en ficción interactiva: "En absoluto puede haber lectura a menos que el lector contribuya activamente a dar forma a la narrativa".

\section{El experimento con el modelo de Comic Multilineal Interactivo.}

El experimento que se presenta fue desarrollado en una escuela de la red pública de Valledupar, Colombia, su población estudiantil proviene de un nivel socio económico medio y bajo, su desempeño en las pruebas institucionales del estado está por debajo de la media nacional. La investigación que nos llevó a plantear el experimento tenía como objetivo identificar los efectos que causa el uso del hipertexto en el desarrollo de competencias para el aprendizaje, esta investigación abordó el reconocimiento del fenómeno desde un nivel descriptivo con un enfoque mixto experimental, ofreciendo interpretaciones de las acciones y comportamientos de los estudiantes observados a través de la investigación, para saber qué es lo que hacen en referencia a las variables estudiadas y las razones por las cuales lo hace, Gay y Mills (2006).

Para la muestra se seleccionaron 30 estudiantes de manera aleatoria entre las edades de 9 a 12 años de ambos sexos, los cuales se dividieron en dos grupos de 15 estudiantes cada uno. El grupo A fue el grupo experimental y el grupo B de control, se planeó exponer los dos grupos a la lectura de un relato escrito por el investigador con el tema de "la convivencia en la escuela", Al grupo B de control se le presentó el relato utilizando el formato del comic tradicional, es decir una historia lineal con imagen y texto dispuesta en viñetas con la estética típica del comic, Montijano (2006). El material para este grupo se diseñó en Power point y fue leído de forma individual en el computador. La historia en la lectura "Soy Actor de Paz?" tiene como objetivo ubicar al estudiante frente la toma de decisiones que lo convertirán en un actor de paz o un actor del conflicto según las decisiones que toma el personaje principal del relato. El comic se presentó para este grupo de control en 5 viñetas cada una dispuesta en una diapositiva, para pasar de una a otra 
solo hubo que hacer clic izquierdo en la pantalla y así se hizo la lectura partiendo de un inicio, pasando por un nudo y llegando a un desenlace final de la historia.

Para el grupo experimental (A) fue diseñado un modelo de comic multilineal interactivo usando la misma historia "Soy Actor de Paz" con imágenes y textos breves, se usó la multimedia para ambientar las escenas con sonidos y acentuar algunas características de los personajes con animación digital. Este modelo de comic Multilineal está desarrollado mediante el software Swish Max 2.0; esta tecnología es adaptable a múltiples plataformas, online y offline, facilita la interactividad y el dinamismo de textos y gráficos; la historia tiene la posibilidad de tomar 27 rutas diferentes para llegar a 3 tipos de finales distintos, todo depende de las decisiones que toma el personaje principal del relato, estas decisiones serán tomadas de manera interactiva por el estudiante mediante un menú de control que se despliega en cada viñeta del comic, en cada escena se ponen a prueba los valores del respeto, la tolerancia, la solidaridad de tal manera que el resultado al final de la historia nos da un indicador del tipo de decisiones que tomó el estudiante para luego plantear una reflexión alrededor de la lectura y de esta manera determinar si es o no es un actor de paz, con la posibilidad de releer la historia, cambiando el rumbo de la narración digital al tomar decisiones distintas a las tomadas en la primera lectura mediante el control interactivo del comic. La tesis era que la multilinealidad en el comic produce motivación e interés por la relectura para explorar todas las posibles rutas que ofrece el relato, incluso después de llegar a un final, el usuario sentirá placer al realizar la lectura nuevamente y sentir el poder de cambiar el desenlace de la historia narrada en el comic, incrementando los índices de comprensión de la lectura en comparación con el grupo de control.

Después de hacer la lectura, además de la observación directa no participante, también fue aplicado un test en ambos grupos A y B, con preguntas agrupadas en las siguientes categorías: perfil del lector, nivel de comprensión lectora, motivación antes y después de la lectura y grado de usabilidad del comic, cada categoría con una serie de preguntas usando la escala de Likert a la cual se le calculó la media para ser comparada con los resultados de cada categoría entre los dos grupos.
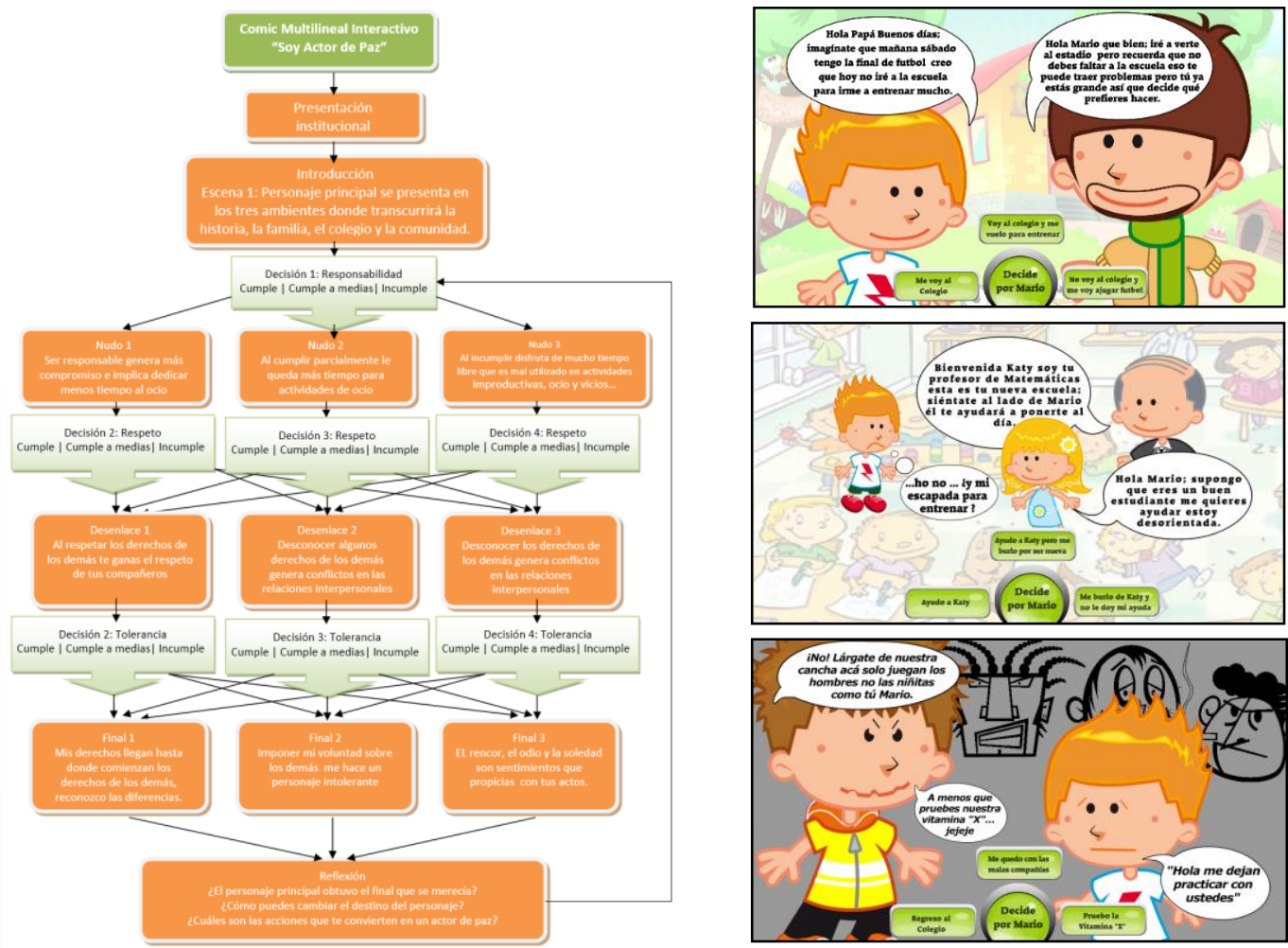

Fuente: Elaboración propia, Figura 4: Estructura Narrativa del Comic Multilineal. 


\section{Resultados y consideraciones finales}

La caracterización de la muestra indica que los estudiantes no tienen el hábito de la lectura, los puntajes obtenidos en las preguntas que indagan sobre el perfil del lector; 6,4 para el grupo de control y 6,5 para el grupo experimental, revelan que la lectura se hace como una exigencia de los trabajos escolares y ocasionalmente para diversión, siendo las redes sociales y los medios digitales las fuentes de lectura más frecuente. Siguiendo los aportes de Strang (1965), Jenkinson (1976) y Smith (1989) para valorar la comprensión lectora se plantearon tres tipos de pregunta en esta categoría: 1) se indagó sobre información explicita presente en el texto para evaluar la comprensión literal, 2) se indujo a la formulación de hipótesis basados en el tema centrar del texto usando su imaginación para evaluar la comprensión inferencial, 3) se pidió que emitieran un juicio valorativo comparando las ideas presentadas por el texto con experiencias cotidianas del lector. Fue interesante descubrir en el grupo experimental que el comic multilineal permitió obtener mayor puntaje de comprensión lectora $(8,9)$ frente al comic tradicional en el grupo de control quienes obtuvieron $(7,3)$, esto verifica el aporte significativo que hace la narrativa digital multilineal para mejorar los niveles de comprensión lectora en la medida que el lector se involucra en el texto hasta el punto de tomar decisiones por sus personajes que van moldeando el rumbo del relato hasta llegar a uno de los múltiples finales posibles.

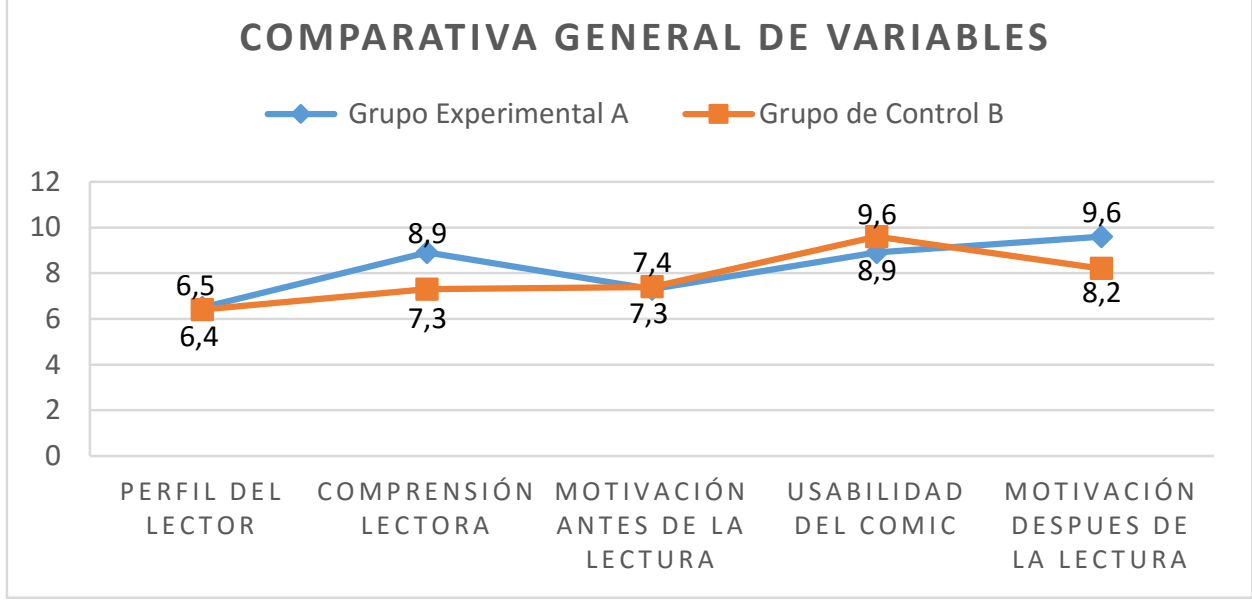

Fuente: Elaboración propia

Figura 6: Grafico comparativo del grupo experimental frente al grupo de control

Al medir la calidad de la experiencia del usuario encontramos que los estudiantes encuentran más fácil de usar el comic tradicional con $(9,6)$ puntos en el grupo de control frente a $(8,9)$ en el grupo experimental, las observaciones muestran que el menú de control de decisiones en la lectura multilineal requiere un corto tiempo de adaptación.

Las preguntas sobre la motivación de ambos grupos antes y después de hacer las lecturas, revelan que la introducción del computador es un factor motivacional positivo en los dos grupos. Sin embargo después de usar el comic multilineal la motivación del grupo experimental aumentó a $(9,6)$ puntos frente a un incremento menor de $(8,2)$ en el grupo de control, según Solé (2009) ayudar a los niños y jóvenes a encontrar motivos propios para leer es una tarea en la que intervienen, la familia, la escuela y la sociedad en su conjunto, el modelo de comic multilineal interactivo motiva la lectura y la relectura del texto digital, se observó en el grupo de control que después de conocer el texto del comic tradicional la expectativa frente al objeto de aprendizaje disminuyó, en contraposición, el comic multilineal no cierra, al final del texto, siempre se abre a la posibilidad de explorar nuevas rutas de la narración digital, donde el estudiante llega por motivación propia y estimulado por el poder de cambiar el final de la historia, se infiere que la interacción 
multilineal en la narrativa digital propuesta por el nuevo modelo de comic genera placer en la lectura y la relectura del texto, según Solé (2009) al lograr una motivación positiva se consigue un lector comprometido e implicado, que desea leer y utiliza su conocimiento y estrategias para cumplir propósitos e intenciones que siente como propios.

Final mente la contribución de este trabajo fue verificar el aporte que hace la multilinealidad a la narrativa digital, comprobando la utilidad del hipertexto en la construcción de objetos de aprendizaje que estimulan la lectura en estudiantes de 9 a 12 años de edad. Es interesante como la propuesta de modelo de comic multilineal abre la posibilidad de que el comic como lo conocemos hoy empiece a sacar verdadero provecho del mundo digital configurándose como un aporte significativo a la evolución del género iconográfico de la narrativa.

Como trabajo futuro, se considera la posibilidad de replicar el experimento con grupos de estudiantes de otros países en Latinoamérica como Brasil, Argentina y Chile. De esta forma validaríamos la eficiencia y la confiabilidad de los instrumentos de investigación y la innovación del modelo de comic multilineal interactivo.

\section{Referencias}

ASTUDILlO, G; WILLGING, P; GARCIA, P. Estado del arte de los repositorios de materiales educativos en Latinoamérica. Facultad de Ciencias Exactas y Naturales UNLP.2011. Disponivel em: $<$ http://sedici.unlp.edu.ar/bitstream/handle/10915/18431/Documento_completo_.pdf?s equence $=1>$ Acesso em: 10 oct. 2015.

CECCHIN, A.S.; REIS, S. C. A prática de multiletramentos no contexto escolar público: relatando experiências na produção de narrativas digitais em aulas de língua portuguesas. Revista Renote, v. 12, n. 2, p. 7, 2014.

CERLALC. El libro electrónico. Tendencias y recomendaciones. 2012. Disponível em: $<$ http://cerlalc.org/wp-content/uploads/2013/05/Libro_Electronico.pdf $>$ Acesso em: 1 jun. 2015.

CORMIER, Dave. What is a MOOC. [Video]. 2010, 4:27. Disponivel em: 〈http://www.youtube.com/watch?v=eW3gMGqcZQc > Accesso en: 8 oct. 2015.

FAILLA, Zoara (org.). Retratos da leitura no Brasil. São Paulo: Impresa Oficial do Estado de São Paulo/ Instituto Pró-Livro, 2012.

GAY, L.R., MILLS, G., AIRASIAN P. Educational Research: Competencies for Analysis and Applications. (8th ed). New Jersey, United States of America: Pearson / Merrill / Prentice Hall. 2006

GUTIERREZ, E. Leer digital: la lectura en el entorno de las TIC. Revista Signo y Pensamiento, Vol. XXVIII, p. 161. Disponível em: $<$ http://revistas.javeriana.edu.co/index.php/signoypensamiento/article/viewFile/3734/33 93) Acesso em: 10 oct. 2015.

HOLTZMAN, Steven. Digital Mantras, The Languages of Abstract and Virtual Worlds. Cambridge, United States of America: The MIT Press. 1994. 
JENKINSON, M. D. Modos de enseñar, en Staiger, R. C. (comp.), La enseñanza de la lectura, Buenos Aires, Huemul. 1976.

LÉVY, P. ¿Qué es lo virtual?, Barcelona, España: Paidos. 1999.

LOPEZ, C. L. Los Repositorios de Objetos de Aprendizaje como soporte a un entorno elearning. (Tesis Doctoral) Universidad de salamanca, España, Salamanca. 2005. Disponivel em: http://gredos.usal.es/jspui/bitstream/10366/56649/1/DIA_Repositoriosobjetos.pdf.pdf Acesso em: 20 oct. 2015.

LÓPEZ, J.C. Uso educativo de los cómics y herramientas para elaborarlos, 2013. Eduteka. Disponivel em:<http://www.eduteka.org/comics.php > Accesso em: 3 oct. 2015.

MONTIJANO, M. C. Breve historia del comic, Jun, 2006. Homines. Disponivel em: $\lfloor$ http://homines.com/comic/comic_01/index.htm\#_edn1>. Acesso em: 21 oct. 2015.

ORIHUELA, J. Narraciones interactivas: el futuro no-lineal de los relatos en la era digital, 1997. Disponivel em: 〈http://www.ucm.es/info/especulo/hipertul/califia.htm> Acesso em: 8 oct. 2015.

PÉREZ, S. El concepto de hipertexto en el periodismo digital. Disertación doctoral no publicada. Departamento de periodismo II, Universidad Complutense de Madid. (2003).

RODRÍGUEZ, J. A. Teoría práctica y enseñanza del hipertexto de ficción. El Relato Digital. Pontificia Universidad Javeriana. 2002. Disponivel em: <http://www.javeriana.edu.co/relato_digital >, Acesso en: 5 oct. 2015.

SALVAT, Guiomar. La expresión digital en presente continuo. Madrid, España: CEESEdiciones. 2000.

SITEAL. El Analfabetismo en América Latina, una deuda social. SITEAL, OEI y UNESCO. 2008. Disponivel em: <http://www.siteal.iipeoei.org/sites/default/files/datodestacado_furosevich_20101130.pdf $>$ Acesso em: 7 oct. 2015.

SMITH, C. B. La enseñanza de la lecto-escritura: un enfoque interactivo, Madrid, Aprendizaje Visor. 1989.

SOLÉ, I. Motivación y lectura. Aula de Innovación Educativa, 2009. Disponivel em: <http://www.cepalcala.org/upload/novedades/archivo_noticia_19_10_09_01_48_26.pdf $>$ Acesso em: 15 oct. 2015.

STRANG, Ruth. Procesos del aprendizaje infantil, Buenos Aires, Paidós. 1965

WILSON, Eydie. Serious Comix - Engaging Students with Digital Storyboards, Ed: SCOMIX, s/1, 2013.

WOLF, Mariane. Proust and the Squid: The Story and Science of the Reading Brain. Harper, Nueva York. 2008. 